\title{
BENDING OF A BATTER PILE DUE TO GROUND SETTLEMENT
}

\author{
Kunio TAKahashi*
}

\begin{abstract}
This paper presents a method of analyzing, with the aid of an electronic computer, the flexural behavior of a batter pile due to ground settlement. In the method used here, a pile was devided into four sections according to ground conditions and Winkler subgrade was assumed for subsiding clay ground. To investigate applicability of the method, both laboratory and field tests were performed. In the laboratory tests, eight steel plate piles, each $1.78 \mathrm{~m}$ long, were used as four coupled piles with inclination angles of $5^{\circ}, 10^{\circ}, 15^{\circ}$, and $20^{\circ}$. In the field tests, four steel pipe piles, each $38.7 \mathrm{~m}$ long, were installed as two couples through an embankment $2.5 \mathrm{~m}$ thick with an inclination angle of $15^{\circ}$. For one of the couples, the two piles were asphalt coated. Strains in the pile shaft increasing with time were measured with the ground settlement in both tests. In addition to the author's method, the elastic finite element analysis and Sato's method were also examined. Consequently, the following points were clarified: (1) The maximum bending moment is proportional to the pile inclination and to the ground surface settlement; (2) Although asphalt coating is useful for negative skin friction even with a batter pile, it seems disadvantageous from the point of view of bending; and (3) While all three analytical methods provide good approximations of the test results, the best agreement was obtained by the author's method.
\end{abstract}

Key words : batter pile, bitumen, computer application, field test, model test, settlement, soft ground, subgrade reaction coefficient (IGC : E 4/E 2)

\section{INTRODUCTION}

Since soft clay layers of considerable thickness are widely deposited in many industrial regions of Japan such as Tokyo and Osaka, problems with pile foundations due to ground settlement are often encountered. For vertical piles the problem is one of negative skin friction which is caused by a force dragging the vertical piles down (Endo, 1969). On batter piles the problem involves bending caused by a force pushing the batter piles down. Although the movement of the ground is the same, the critical phenomena are different for vertical piles and batter piles.

* Chief of the Foundations Laboratory, Soils Division, Port and Harbour Research Institute, Ministry of Transport, 1-1, 3-chome, Nagase, Yokosuka, Kanagawa 239.

Manuscript was received for review on April 23, 1984.

Written discussions on this paper should be submitted before July 1, 1986, to the Japanese Society of Soil Mechanics and Foundation Engineering, Sugayama Bldg. 4F, Kanda Awaji-cho 2-23, Chiyoda-ku, Tokyo 101, Japan. Upon request the closing date may be extended one month. 
It goes without saying that negative skin friction is a momentous problem with pile foundations in port and harbour areas as well (Sawaguchi, 1971; Takahashi et al., 1974; Takahashi and Sawaguchi, 1976). Particularly in these areas, however, the bending of batter piles is an equally serious problem because of the combination of the two facts that pile foundations including batter piles are common and that soft clay layers prevailing in these areas are very wide and thick (Takahashi, 1980). While this problem is considered serious for pile foundations including batter piles in other types of constructions as well, with bridges for example, available studies on the problem are very few in number (Sato et al., 1970; Broms and Fredriksson, 1976 ; Shibata et al., 1982). Therefore, the author finds it worthwhile to complete and publish his experimental studies on this problem concerning the bending of batter piles (Takahashi and Sawaguchi, 1978 ; Takahashi, 1981).

In Sato's method, a batter pile is expressed as an elastic beam subjected to the weight of soil, and supported elastically in the deeper subsoil. A rough sketch of this method is shown in Fig. 1. In calculations using this method, appropriate values must be assumed for the width and the length of the pile, and these values shall hereafter be referred to as the "effective width" and the "effective length", respectively. The area defined by

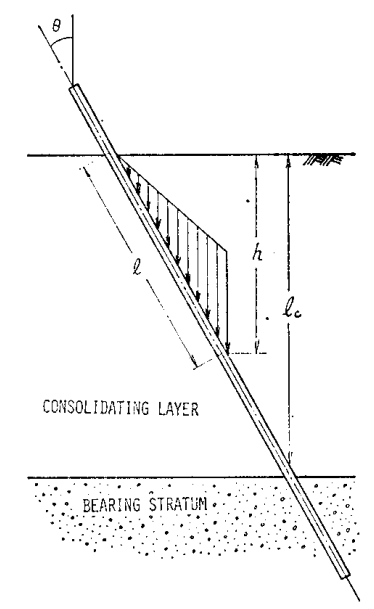

Fig. 1. Model of Sato's method where $l$ is "effective length" these two values is assumed to receive the weight of the soil. Shibata et al. as well as Broms and Fredriksson have assumed subsiding soil to be Winkler ground, but their aim was to gain useful insight into their test results (Shibata et al., 1984). Hence their method is applicable only to the simplest case. The method by Broms and Fredriksson, which utilizes a trigonometric series, is not convenient for general use. The author's method, also assuming Winkler ground, can apply in general to cases with a number of layers, with the aid of an electronic computer. This analysis includes those by Shibata et al., Broms and Fredriksson, and even Sato et al. The most important aim of this paper is to propose this method.

Another main aim of the present paper is to clarify experimentally the behavior of a batter pile in subsiding ground. Asphalt coating on a pile shaft is considered to be an effective method for decreasing negative skin friction. The effect of asphalt coating on the bending of a batter pile when a surrounding ground subsides is a subject of interest and concern, and this is also examined experimentally in the present study.

The experimental results can be used to judge the applicability of the proposed method as well as the other analytical methods, i. e., the finite element method and Sato's method.

\section{THEORETICAL METHOD OF ANALYZ- ING FLEXURAL BEHAVIOR OF A BATTER PILE}

Three methods are examined in this study. The first method is the finite element analysis; both two- and three-dimensional analyses are examined. The next is Sato's method; a brief explanation of this method was provided in the previous section. For lack of space, these methods will not be explained further here, and the reader is referred to other literature.

The third method is described in detail. In this method, a batter pile is assumed to be an elastic beam in Winkler subsoil. 


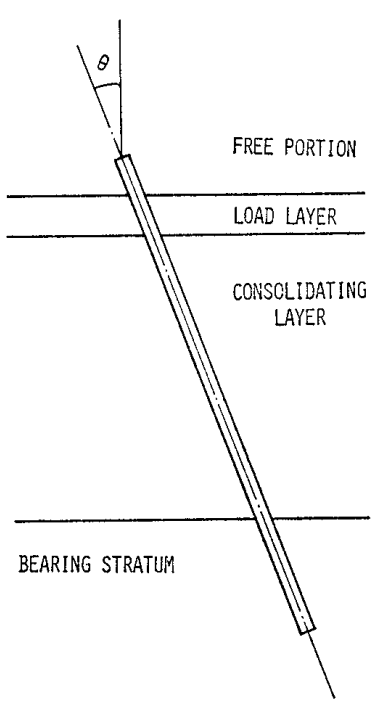

Fig. 2. Model of the author's method

The pile is loaded by the upper part of the subsiding ground proportionally to the product of the coefficient of subgrade reaction and the relative displacement between the pile deflection and the component of ground settlement normal to the pile axis; the pile is supported by the lower part of the ground in the same way. These phenomena can be rationally expressed by the present method together with the assumption of a number of layers, using an electronic computer. Fig. 2 illustrates a simple model for this method of calculation.

The assumption of Winkler subsoil is expressed by the equation

$$
\frac{E I}{B} \frac{d^{4} y}{d x^{4}}=p=k(S(x) \sin \theta-y)
$$

where $E I=$ flexural rigidity of the pile;

$B=$ breadth of the pile ;

$y=$ deflection of the pile normal to pile axis ;

$x=$ distance from pile tip along pile axis ;

$p=$ subgrade reaction ;

$k=$ coefficient of subgrade reaction ;

$S(x)=$ ground settlement as a function of position ;

$\theta=$ inclination angle of the batter pile.

The first layer from the pile tip in Fig. 2 is a bearing stratum. Since the function $S(x)$ is naturally assumed to be zero in a bearing stratum, Eq. (1) becomes the wellknown formula expressing horizontal pile behavior under elastic subgrade reaction (Terzaghi, 1943).

The second layer from the pile tip represents a consolidating layer, and it is the most significant layer in this analysis. Assuming one-dimensional consolidation, $S(x)$ may be considered a function of depth and time. When $S(x)$ is expressed by a polynomial of up to third order, Eq. (1) can easily be solved in the form

$$
y=A_{1} z_{1}+A_{2} z_{2}+A_{3} z_{3}+A_{4} z_{4}+S(x) \sin \theta
$$

where $A_{1}-A_{4}$ are constants and

$$
\begin{aligned}
& z_{1}=\cos \beta x \cdot \cosh \beta x \\
& z_{2}=\frac{1}{2}(\sin \beta x \cdot \cosh \beta x+\cos \beta x \cdot \sinh \beta x) \\
& z_{3}=\frac{1}{2} \sin \beta x \cdot \sinh \beta x \\
& z_{4}=\frac{1}{4}(\sin \beta x \cdot \cosh \beta x-\cos \beta x \cdot \sinh \beta x) \\
& \beta=\sqrt[4]{-\frac{B k}{4 E I}} \\
& S(x)=\alpha_{0}+\alpha_{1} x+\alpha_{2} x^{2}+\alpha_{3} x^{3}
\end{aligned}
$$

$z_{1}-z_{4}$ are defined as above for the sake of convenience in further calculation.

The third-order polynomial expression for a settlement distribution is considered usable and appropriate for the following reasons. The isochrone of strain under consolidation is similar in shape to a parabolic curve defined by the second-order polynomial. Since the settlement is an integrated value of strain in the ground, it is expressed by the thirdorder polynomial including the error shown in Fig. 3. Consequently, Eq. (4) represents
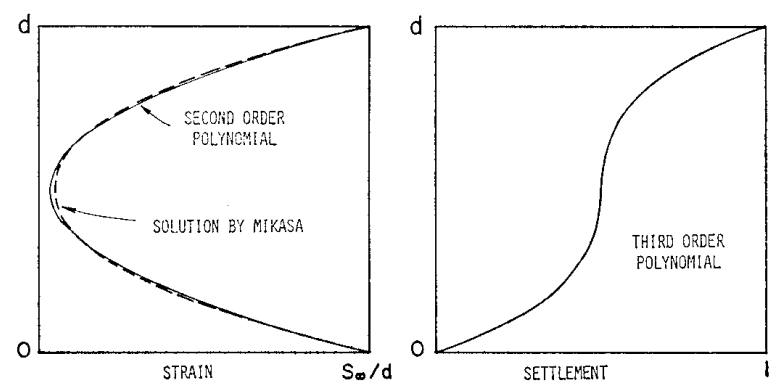

Fig. 3. Isochrone of strain and integrated settlement distribution 
a settlement distribution at a time in the consolidation process with a given value of consolidation degree. Entering the necessary values listed below, the actual expression $S(x)$ becomes

$$
\begin{aligned}
S(x)= & S_{\infty}\left\{\frac{x}{d / \cos \theta}-(1-U)\left(\frac{x}{d / \cos \theta}\right)^{2}\right. \\
& \left.\times\left(3-2 \frac{x}{d / \cos \theta}\right)\right\}
\end{aligned}
$$

where $S_{\infty}=$ final settlement of the ground surface ;

$d=$ initial thickness of the consolidation layer;

$U=$ degree of consolidation.

In order for Eq. (5) to be rational, $U \geqq 1 / 3$; in other words, Eq. (5) should not express the early stage of consolidation when strain is concentrated in the area close to the drainage surfaces.

The third layer from the pile tip in Fig. 2 is that functioning as a load. A load layer corresponds to an embankment, which is often a cause of ground settlement. The assumption of this load layer is natural and appropriate in this case, since it is unreasonable that the area near the ground surface should press a pile at higher load than the deeper area. As a consequence, the expression of the right-hand side of Eq. (1) for this load layer is changed:

$$
\frac{E I}{B} \frac{d^{4} y}{d x^{4}}=p=r\left(x_{0}-x\right) \sin ^{2} \theta \cos \theta
$$

where $\gamma=$ unit weight of the load layer;

$x_{0}=$ distance from the pile tip to the point at the top surface of the load layer along the pile axis.

Eq. (6) can easily be integrated into the expression

$y=A_{1}+A_{2} x+A_{3} x^{2}+A_{4} x^{3}+A_{5} x^{4}+A_{6} x^{5}$

where $A_{1}-A_{4}$ are constants and

$$
\begin{aligned}
& A_{5}=\frac{1}{24} \frac{B \gamma}{E I} x_{0} \sin ^{2} \theta \cos \theta \\
& A_{6}=-\frac{1}{120} \frac{B \gamma}{E I} \sin ^{2} \theta \cos \theta
\end{aligned}
$$

The fourth section from the pile tip in Fig. 2 is the free portion, so that $k$ is zero in this part. Consequently, the solution of Eq.
(1) is

$$
y=A_{1}+A_{2} x+A_{3} x^{2}+A_{4} x^{3}
$$

In order to analyze pile behavior with boundary conditions and continuity conditions, it is convenient to write the values for deflection, deflection angle, bending moment, shear force, and soil pressure in the form of a vector

$$
\{Y\}=\left\{\begin{array}{l}
y \\
y^{\prime} \\
y^{\prime \prime} \\
y^{\prime \prime \prime} \\
y^{\prime \prime \prime \prime}
\end{array}\right\}=\left\{\begin{array}{c}
y \\
y^{\prime} \\
-\frac{M}{E I} \\
-\frac{Q}{E I} \\
\frac{B P}{E I}
\end{array}\right\}
$$

The vector expressing the pile behavior in the first stratum from the pile tip in Fig. 2, the bearing stratum, is

$$
\begin{aligned}
& \{Y\}=\left(\begin{array}{cccc}
z_{1} & z_{2} & z_{3} & z_{4} \\
-4 \beta z_{4} & \beta z_{1} & \beta z_{2} & \beta z_{3} \\
-4 \beta^{2} z_{3} & -4 \beta^{2} z_{4} & \beta^{2} z_{1} & \beta^{2} z_{2} \\
-4 \beta^{3} z_{2} & -4 \beta^{3} z_{3} & -4 \beta^{3} z_{4} & \beta^{3} z_{1} \\
-4 \beta^{4} z_{1} & -4 \beta^{4} z_{2} & -4 \beta^{4} z_{3} & -4 \beta^{4} z_{4}
\end{array}\right) \\
& \times\left(\begin{array}{l}
A_{1} \\
A_{2} \\
A_{3} \\
A_{4}
\end{array}\right)=[Z]\{A\}
\end{aligned}
$$

In order to write the vector for the second layer, the most important consolidating layer, the ground settlement is also rewritten in the form of a vector

$$
\{S\}=\left\{\begin{array}{l}
S \\
S^{\prime} \\
S^{\prime \prime} \\
S^{\prime \prime \prime} \\
S^{\prime \prime \prime \prime}
\end{array}\right\}=
$$

$\left\{\begin{array}{l}S_{\infty}\left\{\frac{x}{d / \cos \theta}-(1-U)\left(\frac{x}{d / \cos \theta}\right)^{2}\left(3-2 \frac{x}{d / \cos \theta}\right)\right\} \\ \frac{S_{\infty}}{d / \cos \theta}\left\{1-6(1-U) \frac{x}{d / \cos \theta}\left(1-\frac{x}{d / \cos \theta}\right)\right\} \\ -\frac{6 S_{\infty}}{(d / \cos \theta)^{2}}(1-U)\left(1-2 \frac{x}{d / \cos \theta}\right) \\ \frac{12 S_{\infty}}{(d / \cos \theta)^{3}}(1-U) \\ 0\end{array}\right\}$

Consequently, the equation expressing the 
pile behavior in the second layer is

$$
\{Y\}=[Z]\{A\}+\{S\}
$$

The equation for the load layer is

$$
\begin{aligned}
\{Y\} & =\left(\begin{array}{cccc}
1 & x & x^{2} & x^{3} \\
0 & 1 & 2 x & 3 x^{2} \\
0 & 0 & 2 & 6 x \\
0 & 0 & 0 & 6 \\
0 & 0 & 0 & 0
\end{array}\right)\left\{\begin{array}{l}
A_{1} \\
A_{2} \\
A_{3} \\
A_{4}
\end{array}\right\} \\
& +\left(\begin{array}{rrr}
x^{4} & x^{5} \\
4 x^{3} & 5 x^{4} \\
12 x^{2} & 20 x^{3} \\
24 x & 60 x^{2} \\
24 & 120 x
\end{array}\right)\left\{\begin{array}{l}
\frac{1}{24} \frac{B r}{E I} x_{0} \sin ^{2} \theta \cos \theta \\
-\frac{1}{120} \frac{B r}{E I} \sin ^{2} \theta \cos \theta
\end{array}\right\} \\
= & {[X]\{A\}+\{C\} }
\end{aligned}
$$

Since the equation for the free portion can be obtained by making the load of the load layer zero,

$$
\{Y\}=[X]\{A\}
$$

Although the vectors expressing pile behavior introduced above are five-dimensional, the four-dimensional vectors are used without the fifth value of soil pressure in order to solve the equations. In the model shown in Fig. 2, sixteen constants could be solved by the use of twelve continuity conditions at three boundaries between the layers and of four boundary conditions at pile top and pile tip.

\section{MODEL TESTS}

The test apparatus is shown schematically in Fig. 4. The testing tank, made of steel, is $2.52 \mathrm{~m}$ in diameter (area $=5 \mathrm{~m}^{2}$ ) and $1.7 \mathrm{~m}$ in height, and has two drain pipes in the bottom. The clay used for the consolidating ground has the following index properties: $w_{L}=89.8 \%, w_{p}=35.2 \%$ and the specific gravity $G_{s}=2.72$. It is remolded completely and saturated fully with an electric remolding machine before being put into the testing tank. When the clay layer consolidates under load, the water that is released into the upper and lower sand layers is drained away; for this purpose the upper level is connected to the lower level by a reinforced hose. In order to eliminate the friction between the tank wall and the subsiding

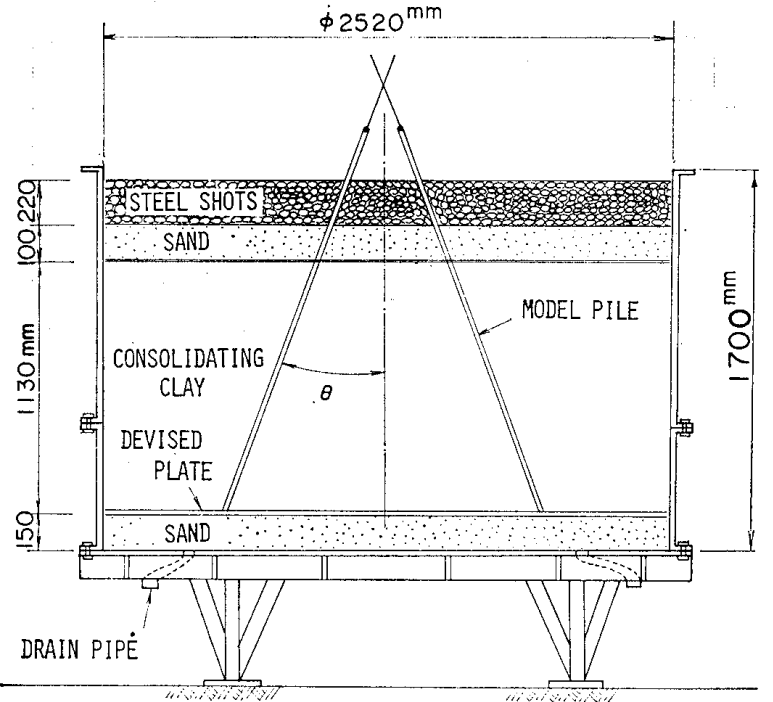

Fig. 4. Model test apparatus

soil during consolidation, a coat of grease and a thin vinyl sheet are attached to the tank wall before the soils are put into the tank.

The piles used are steel plates with a length of $1.78 \mathrm{~m}$, a breadth of $75 \mathrm{~mm}$, and a thickness of $9 \mathrm{~mm}$. Eight piles are used. Since all of the piles are instrumented, the bending strain at seventeen points along each pile can be measured. The piles are inserted by means of a special device into the remolded clay layer with the prescribed inclination angles of $5^{\circ}, 10^{\circ}, 15^{\circ}$, and $20^{\circ}$. The pile tips are hinged at the boundary between the consolidating clay layer and the lower draining sand layer with a specially-devised steel plate. The pile tops are also hinged between every two piles having the same inclination angle.

For the load layer, $50 \mathrm{kN}$ of steel shots with a diameter of $2.5 \mathrm{~mm}$ are used. Since the cross-sectional area of the testing tank is $5 \mathrm{~m}^{2}$, a consolidation pressure of $10 \mathrm{kN} / \mathrm{m}^{2}$ is created.

Ground settlement, pile deflection, and bending strain induced in the piles were measured for one hundred days. The curve in Fig. 5 represents the settlement of the ground surface(i. e., the surface of the steel shot layer), which is obtained by averaging the measured values of four dial gauges. 


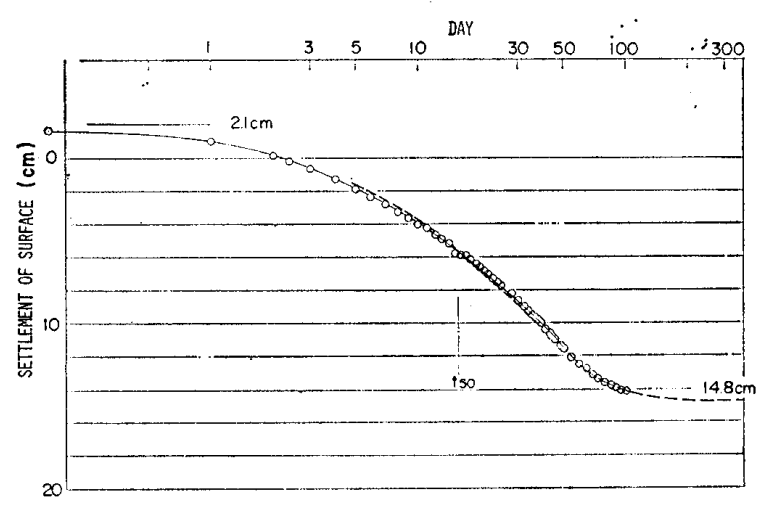

Fig. 5 Settlement of ground surface

The total settlement was observed to be $16.4 \mathrm{~cm}(=2.1 \mathrm{~cm}+14.3 \mathrm{~cm})$ after one hundred days. Since the estimated value of the final settlement by the curve fitting method is $16.9 \mathrm{~cm}(=2.1 \mathrm{~cm}+14.8 \mathrm{~cm})$, the degree of consolidation is $97 \%$ at the time of the final measurement. Fig. 6 shows the distributions of the unconfined compressive strength $q_{u}$ and the wet unit weight $\gamma_{t}$ of the clay layer, which were measured after the tests.

Bending strain in the pile material is measured by strain gauges at seventeen points, placed every $10 \mathrm{~cm}$ along each pile. From the bending strain data, the bending moment can easily be calculated. The distribution of the bending moment of the piles for which $\theta=20^{\circ}$ is shown in Fig. 7 as one exam-

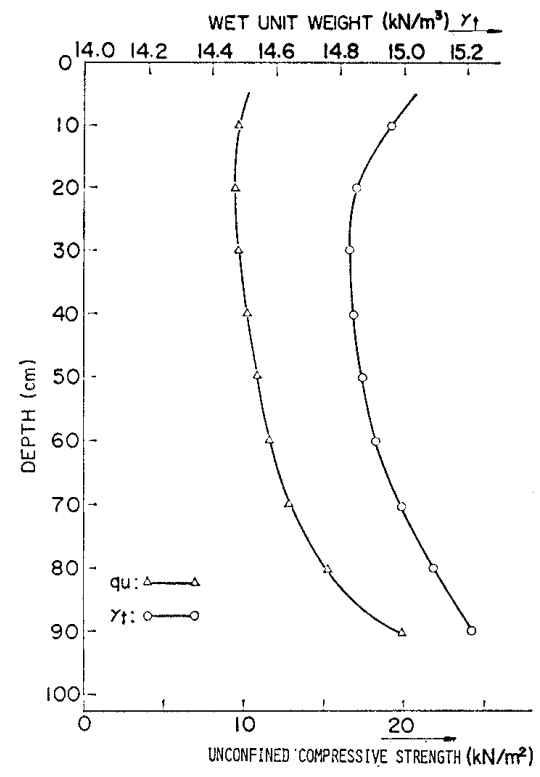

Fig. 6. Distributions of wet unit weight and unconfined compressive strength of model ground

ple. Based on the general characteristics in Fig. 7, which hold true also in the other three cases with different inclination angles, the distributions of shear force and soil pressure can be drawn as in Fig. 8 . Some points are worth noting: while the upper part of the subsiding layer naturally pushes the batter pile down, the lower part pushes it up; and at the hinged point of the pile tip, the pile is subjected to a downward force
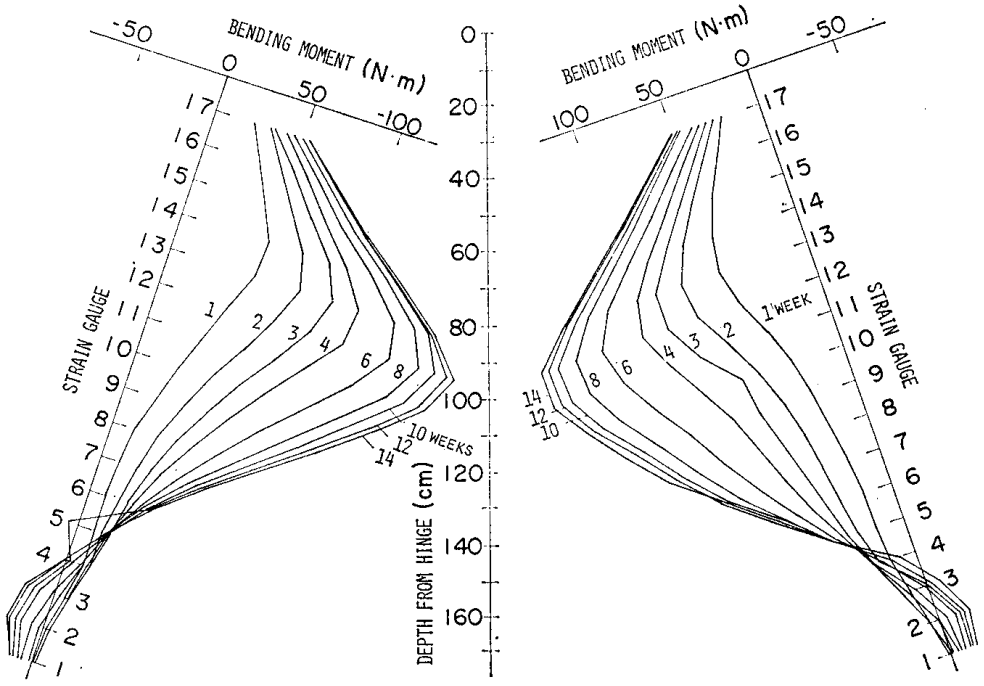

Fig. 7. Distributions of bending moment of piles for which $\theta=20^{\circ}$

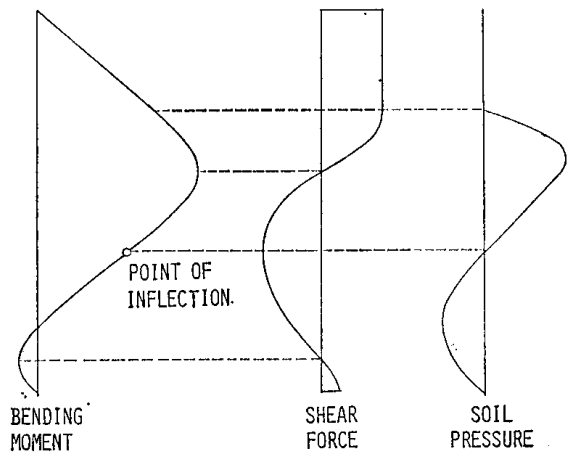

Fig. 8. Distributions of bending moment, shear force, and soil pressure 


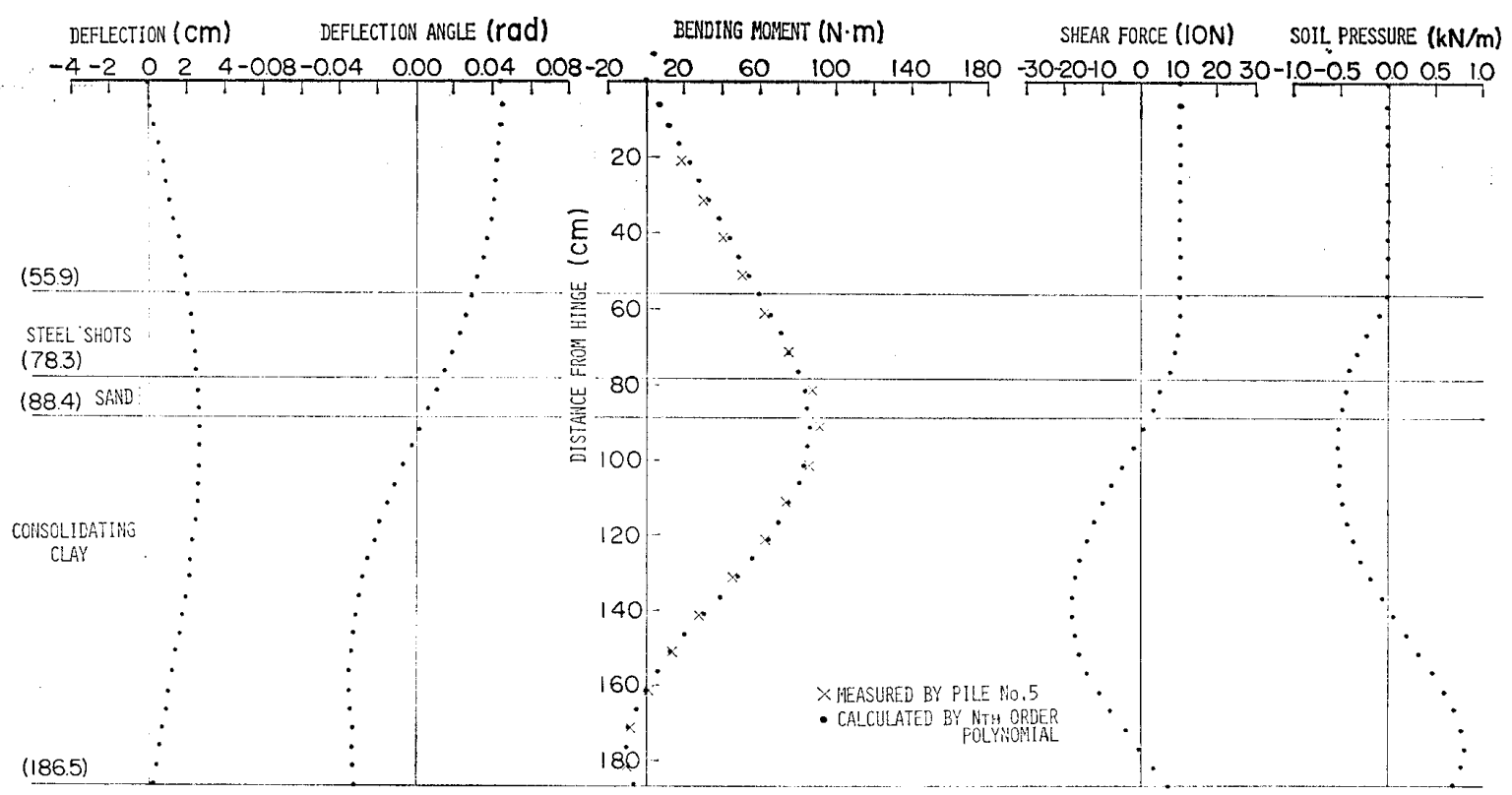

Fig. 9. Integration and differentiation by approximate calculation assuming a $n$th order polynomial for the bending moment distribution of pile for which $\theta=10^{\circ}$

which prevents the pile tip from coming up.

The deflection angle and deflection of a pile can be obtained by integration, and the shear force and soil pressure by differentiation. An actual example of the calculation is seen from Fig. 9 for the case of an inclination angle of $10^{\circ}$. Fig. 10 shows increases of the bending moments with time at the seventeen points for pile No.1, the inclination angle of which is $20^{\circ}$. The maximum benciing moment approaches a stable value

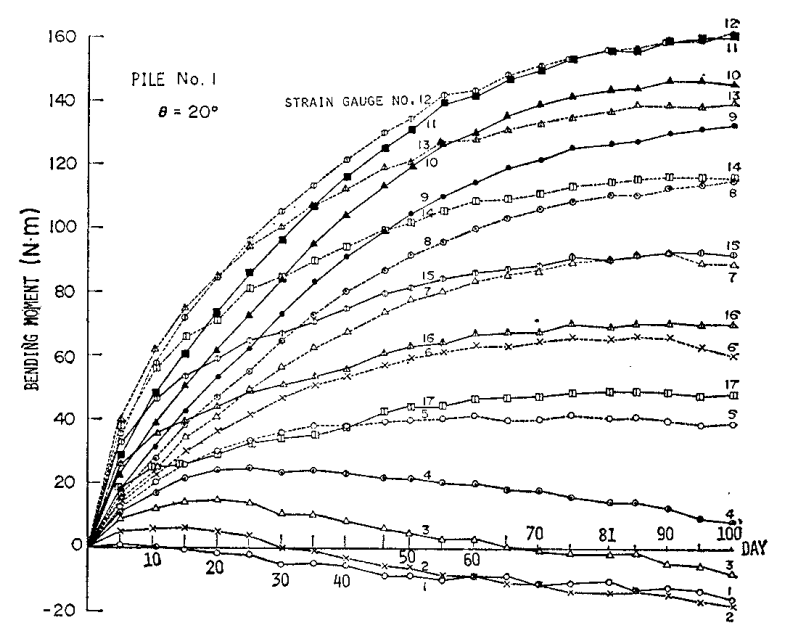

Fig. 10. Increase of bending moment of pile for which $\theta=20^{\circ}$ in one hundred days. Fig. 11 indicates that the maximum bending moment increases proportionally to the inclination angle. Fig. 12 reveals a linear relation between the maximum bending moment and the settlement.

The pile deflection was measured by dial gauges at two points on every pile. With this measurement, any movement of a pair of piles can be computed. Among the relations concerning the movement of the pile top, two particularly significant relations are

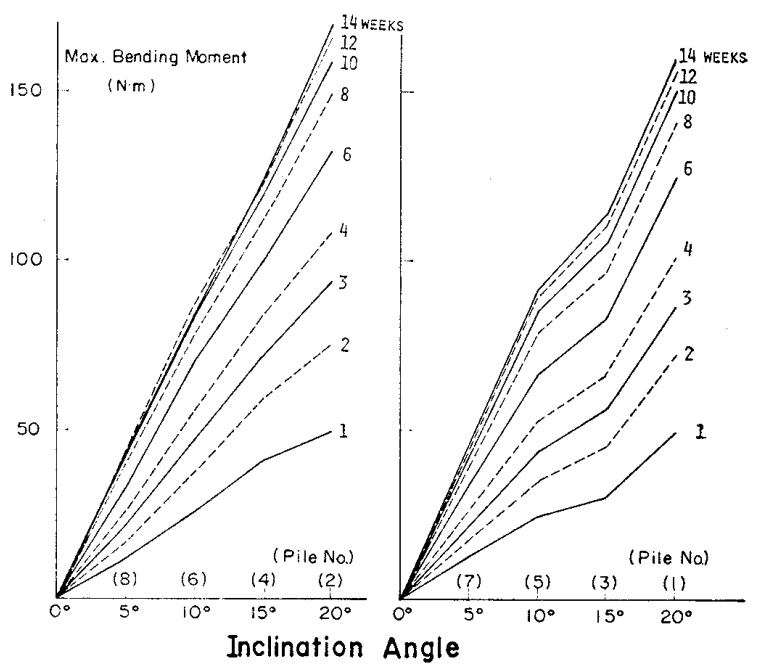

Fig. 11. Maximum bending moment versus pile inclination 


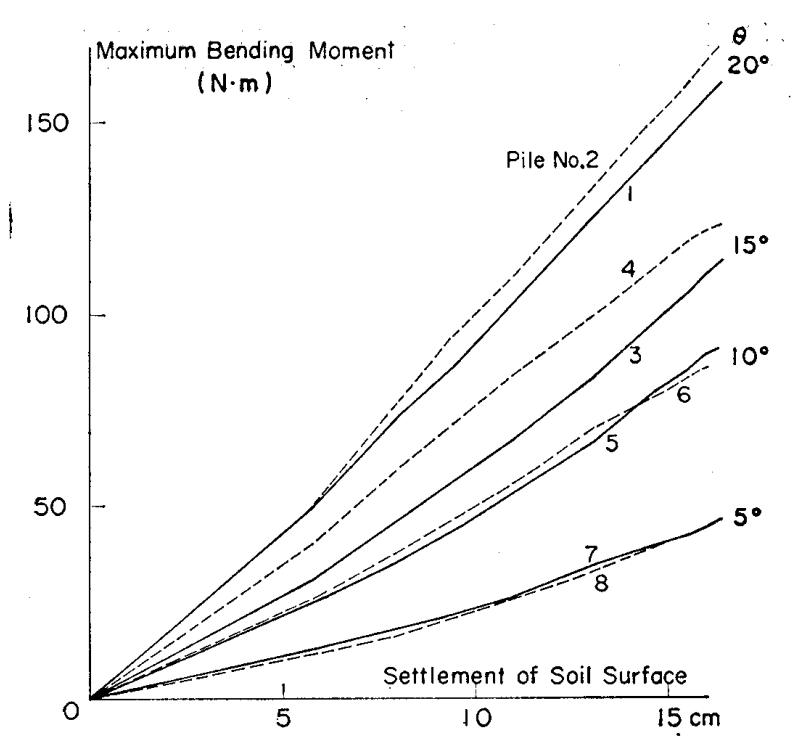

Fig. 12. Maximum bending moment versus settlement

illustrated in Figs. 13 and 14. Fig. 13 shows roughly proportional relations between the inclination angle and the vertical displacement of pile top, and Fig. 14 shows linear relations between the inclination angle and the change in the included angle.

\section{NUMERICAL ANALYSIS OF MODEL TESTS}

The finite element analysis was carried out here based on the assumption of elasticity for the soils and piles. Two-dimentional analysis was performed initially, but the results were far out of line with the experimental data. As the second step, threedimensional analysis was performed for the batter piles having inclination angles of $10^{\circ}$ and $20^{\circ}$.

The steel shot layer and the upper sand layer are assumed to be load, the clay layer analysis model is a series of brick-shaped elements, the pile analysis models are threedimensional beam elements, and springs are assumed between the pile surface and the surrounding soil. Since the bending of a batter pile is a phenomenon concerning ground settlement due to one-dimensional consolidation, Young's modulus $E_{s}$ of the clay is assumed to be $44 \mathrm{kN} / \mathrm{m}^{2}$ from its

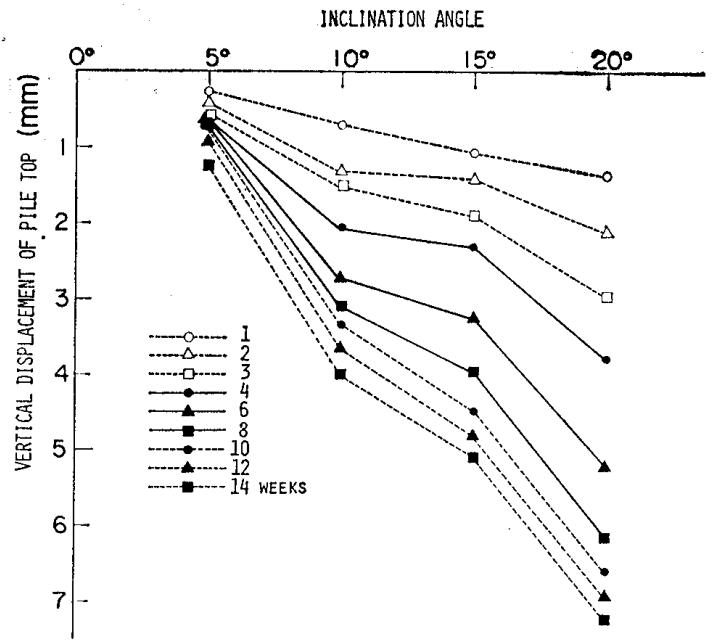

Fig. 13. Vertical displacement of pile top versus pile inclination

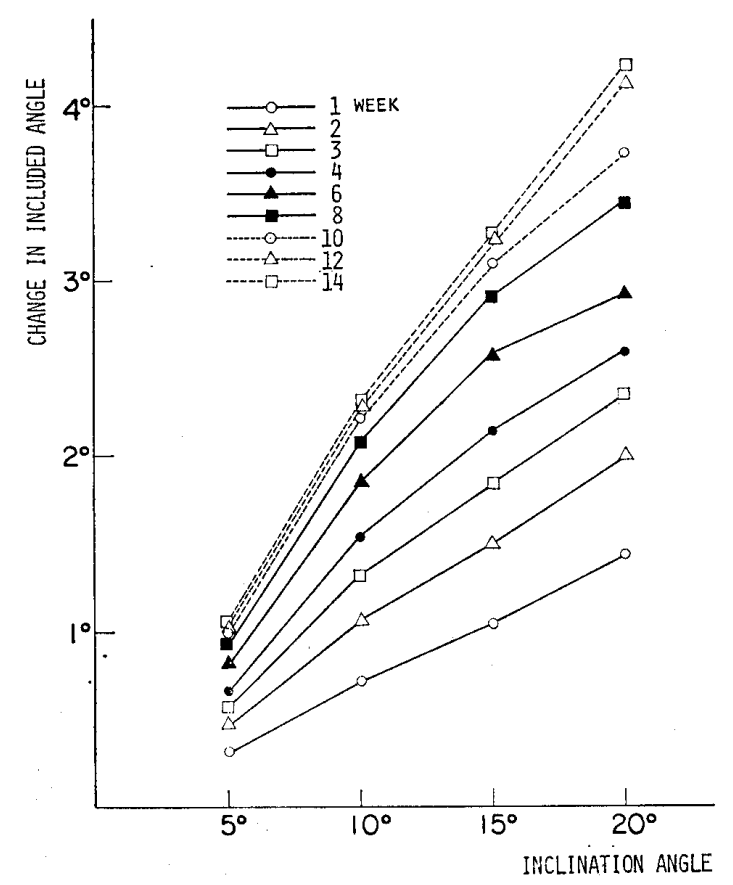

Fig. 14. Change in included angle of coupled piles versus pile inclination

coefficient of volume compressibility $m_{v}=15$ $\mathrm{m}^{2} / \mathrm{MN}$, and Poisson's ratio $\nu=1 / 3$ is derived from its coefficient of earth pressure at rest, $K_{0}$, which is assumed to be 0.5 .

Both calculations for the piles having inclination angles of $20^{\circ}$ and $10^{\circ}$ agree well with the respective test results. As an example, the calculation results for the $20^{\circ}$ case are shown in Fig. 15, along with the test results. 


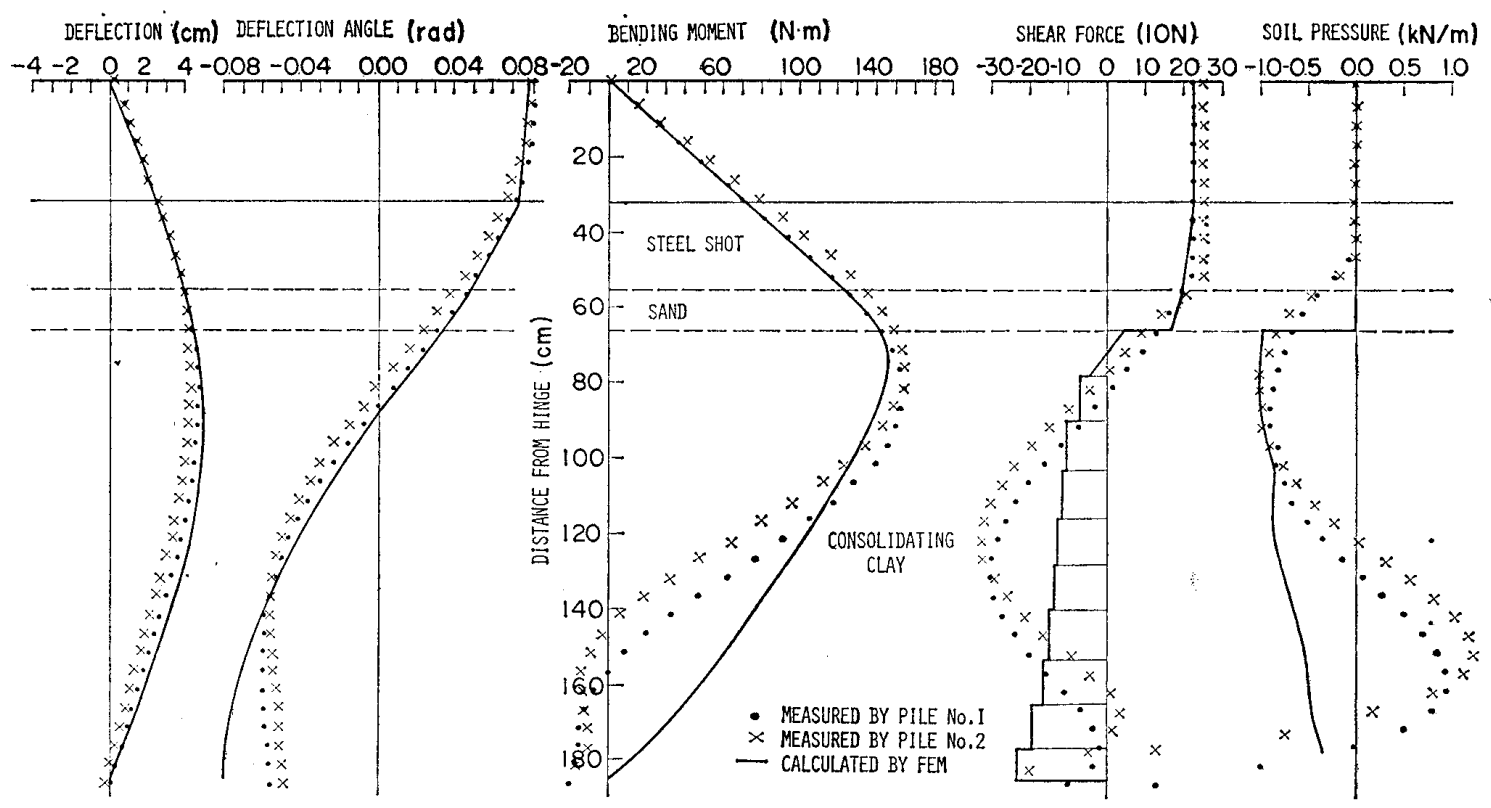

Fig. 15. Calculated results by finite element analysis of pile for which $\theta=20^{\circ}$ where measured values are approximated in the same manner as in Fig. 9

The maximum bending moment, as one of the most important values, is in good agreement with the test results. While the distribution of bending moment values does not agree in the deeper area, this discrepancy could be improved if $E_{s}$ were increased with the depth, in accordance with the fact that the unconfined compressive strength $q_{u}$ in- creases with depth as seen in Fig. 6.

The model of Sato's method was illustrated in Fig. 1. Although Sato et al. show a method for doing the calculations by hand, an electronic computer was used in the present study for the sake of convenience. In this method, the "effective width" and the "effective length" of the pile must be as-

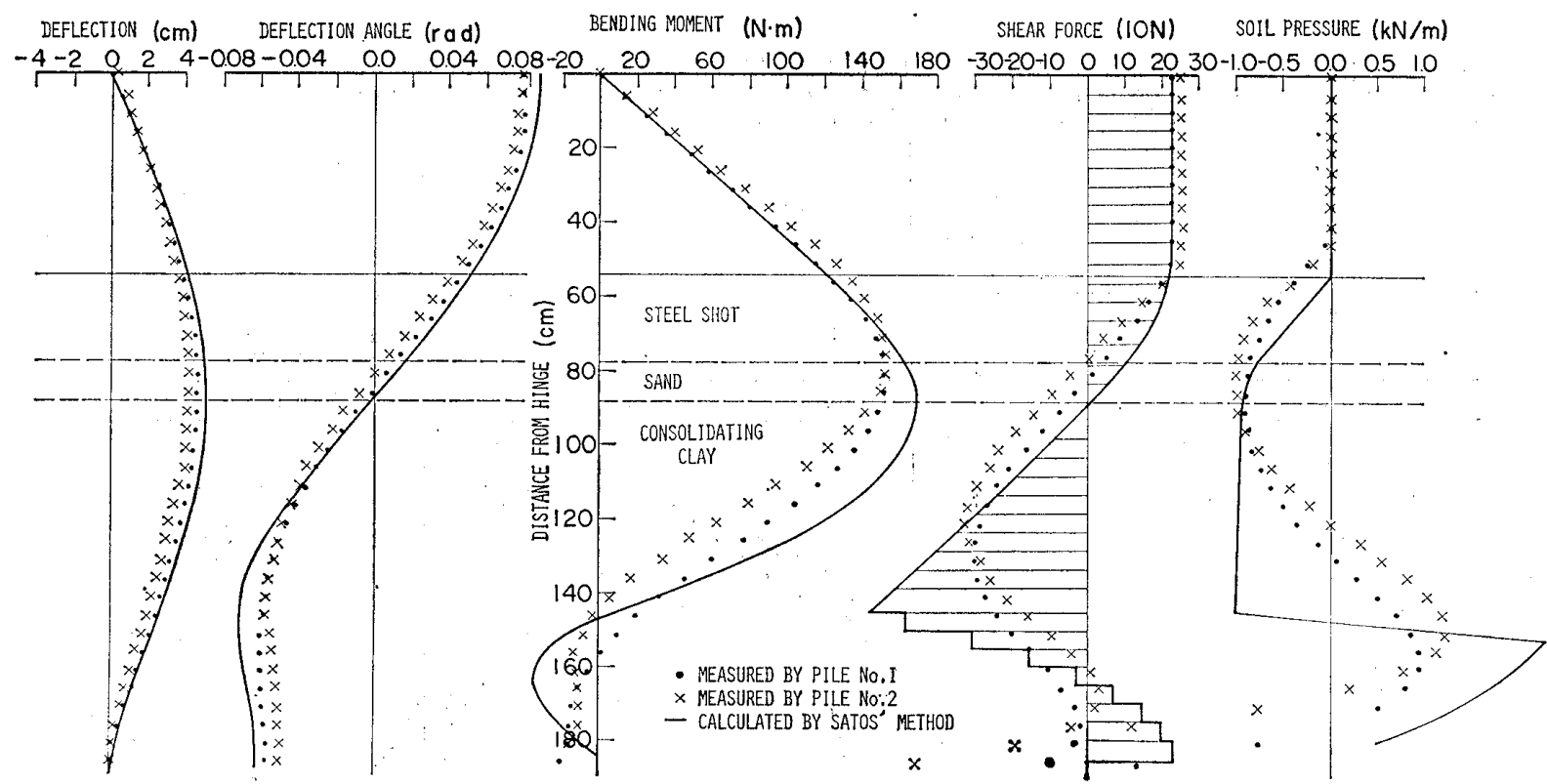

Fig. 16. Calculated results by Sato's method of pile for which $\theta=20^{\circ}$ where measured values are approximated in the same manner as in Fig. 9 
sumed. With regard to the width, Sato et al. have recommended 3 as a width factor, which means that a width of three times the real breadth of the pile receives the soil weight. The length seems difficult to determine, but important. Since the most appropriate ratio of the "effective length" to the actual length within the consolidating clay layer was 0.6 for the model tests, the calculation results of the ratio of 0.6 and of the inclination angle of $20^{\circ}$ are shown in Fig. 16 along with the test results. Good agreement was obtained by assuming the $k$ value for elastic soil reaction to be $2 \mathrm{MN} / \mathrm{m}^{3}$.

A model of the author's method is illustrated in Fig. 17. Calculations were carried out for the following three cases:

1) elastic soil reaction is assumed only for the clay layer, and both the sand layer and the steel shot layer are assumed to be load layers ;

2) elastic soil reaction is assumed for both clay and sand layers, and the steel shot layer is assumed to be a load layer;

3) elastic soil reaction is assumed for all three layers.

The most appropriate results were obtained in the case 2), and the coefficient of soil reaction was $3 \mathrm{MN} / \mathrm{m}^{3}$ as written in Fig. 18.

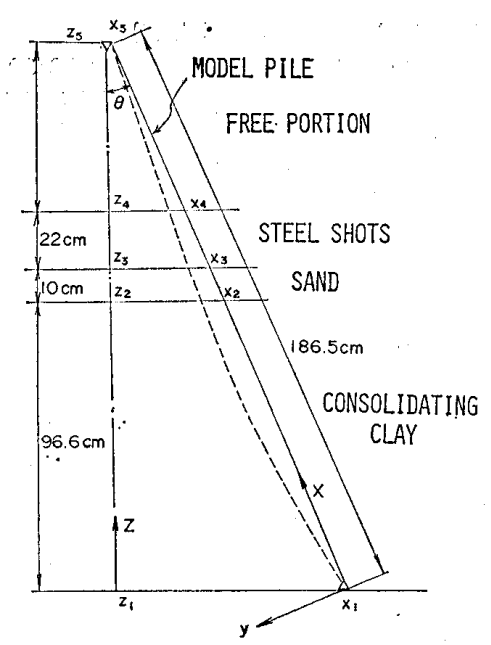

Fig. 17. Model of the author's method for the model tests where length of free portion changes according to $\theta$

The value of $3 \mathrm{MN} / \mathrm{m}^{3}$ is the average not only of the clay layer but also of the upper sand layer. It is judged to be reasonable in consideration of the unconfined compressive strength $q_{u}$ shown in Fig. 6, and also in light of the fact that the value is close to $2 \mathrm{MN} / \mathrm{m}^{3}$ for Sato's method.

Better results were obtained by multiplying the weight of the steel shot, as a load layer, by 10 ; the influence of this value was slight, however. This value can also be referred

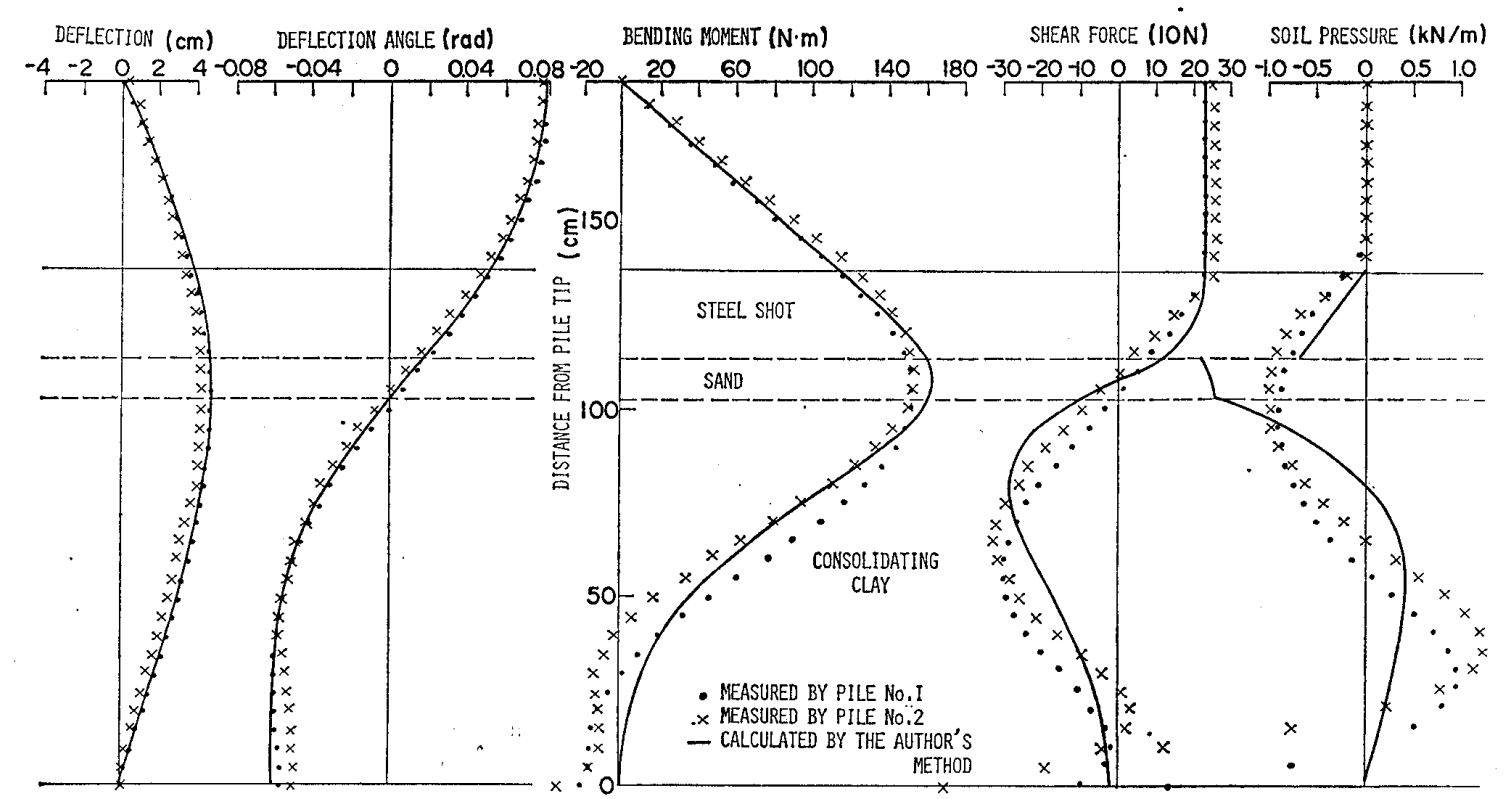

Fig. 18. Calculated results by the author's method of pile for which $\theta=20^{\circ}$ where measured values are approximated in the same manner as in Fig. 9 
to as the width factor. In Sato's method, the width factor used for multiplication was 3 , which is the same value that Broms (1964) has used for multiplying the passive Rankine earth pressure to find the ultimate lateral earth pressure in his method for estimating lateral pile resistance in sand. We believe that the reason this value was as great as 10 in the model tests is that a large magnitude of weight was concentrated on the piles as the steel shots became rusty during the tests. Among the three methods discussed above, the results of the author's method have the best agreement with the test results using the appropriate coefficients.

\section{FIELD TESTS}

With the model tests, the agreement results discussed above were obtained by the three different kinds of analysis. Generally speaking, however, model tests are not sufficient to simulate real phenomena. As a next step, we then performed field tests using prototype piles. In the field tests, the flexural behavior of prototype batter piles as well as those with asphalt coating were observed for one year, and cyclic lateral loading tests of the piles were performed after the end of the period of observation. The properties of the ground are shown in Fig. 19. The soft clayey soil deposit including shell continues from the surface to a depth of $30 \mathrm{~m}$, over the stratum of clay including gravel with an $N$ value of about 20, which is practically incompressible and considered to be able to support the test piles.

First, an embankment of $3000 \mathrm{~m}^{3}$ was made, with a thickness of $2.5 \mathrm{~m}$ and an area of $1200 \mathrm{~m}^{2}$. The soft clay layer $30 \mathrm{~m}$ thick consolidates under this weight. Next, four test piles (steel pipe piles $\phi 508 \times t 9 \times l 38700$ $\mathrm{mm}$ ) were driven in with an inclination angle of $15^{\circ}$, two of them being asphalt coated. The two coated piles were hinged at the top, and so were the other two uncoated piles. Since strain gauges were attached at the points on the pile surface illustrated in Fig. 19, both bending moment and axial force could be determined. The items of measurement, their respective measuring devices, and the numbers of devices are listed in Table 1 .

The data are classified into the following four categories:

1) settlement of ground (settlement of ground surface and distribution of ground settlement),

2) pore water pressure (distribution in the

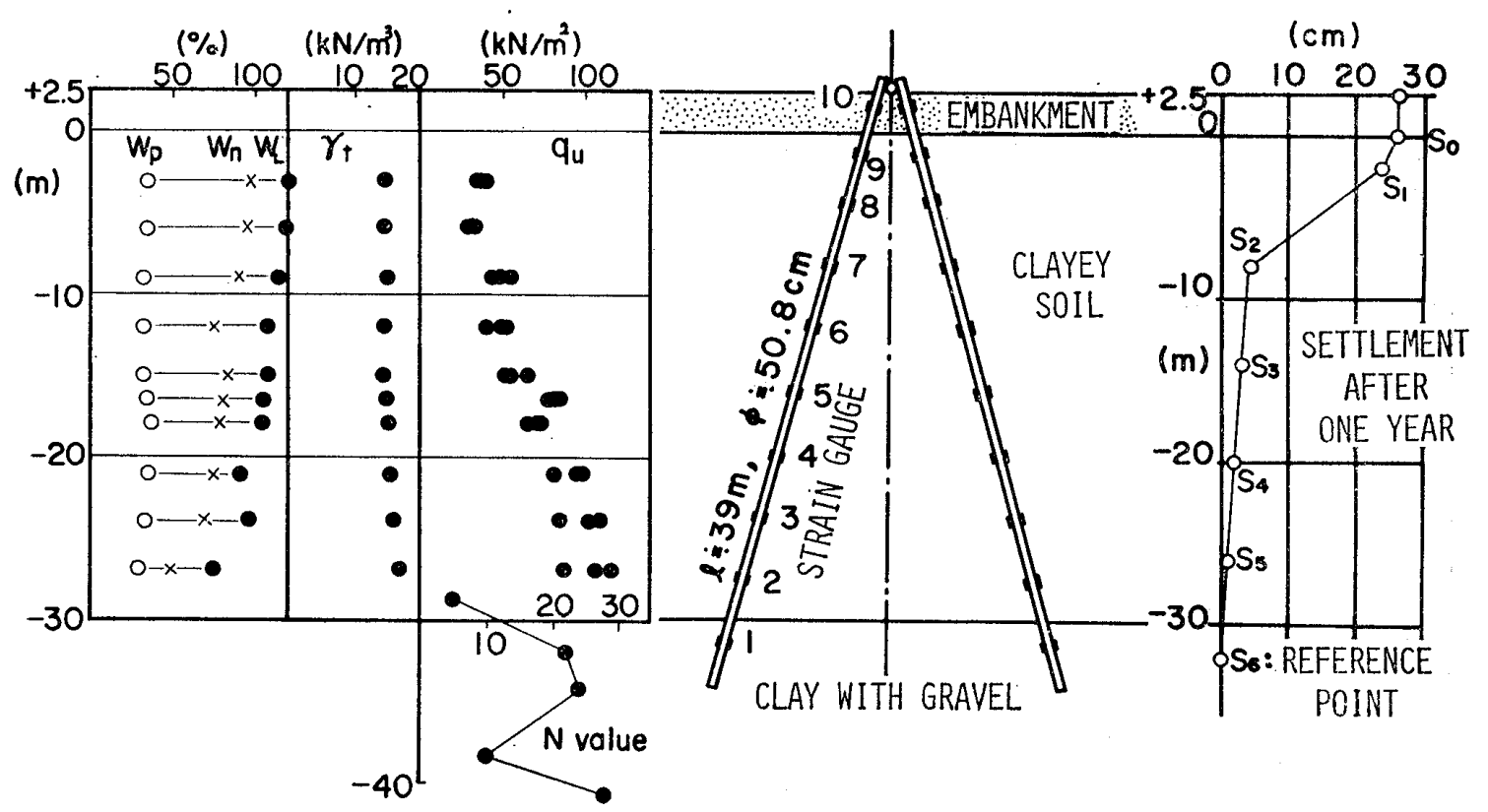

Fig. 19. Rough sketch of the field tests and soil properties of the ground with settlement distribution after one year 
Table 1. Measured items and devices for measurement

\begin{tabular}{|c|c|c|c|}
\hline & Measured item & Device for measurement & $\begin{array}{l}\text { No. of } \\
\text { devices }\end{array}$ \\
\hline \multirow{4}{*}{ Pile } & Strain in pile shaft & Strain gauge & 80 \\
\hline & Deflection angle of pile top & Electric inclinometer & 4 \\
\hline & Settlement of pile top & Level & 4 \\
\hline & Horizontal displacement of pile top & Transit & 2 \\
\hline \multirow{3}{*}{$\begin{array}{l}\text { Surrounding } \\
\text { ground }\end{array}$} & Settlement in the ground & Settling device and level & 6 \\
\hline & Settlement of ground surface & Leve1 & 20 \\
\hline & Pore water pressure in the ground & Electric pore water pressure meter & 5 \\
\hline
\end{tabular}

ground),

3) deformation of piles (vertical and horizontal displacements of pile heads, deflection angle of pile heads, contraction of piles, and penetration of pile tips),

4) bending moment and axial force in piles.

The ground settlement increases with time, as indicated in Fig. 20, and its distribution after one year is drawn on the righthand side of Fig. 19. As seen in the figure, the part from the original ground surface to a depth of $8 \mathrm{~m}$ is the main area of consolidation. Since the measurement of pore water pressure gave totally unexpected values at three out of the five points, these data could not be used for analysis.

A comparison between the pile deformation values for the coated piles (A and B) and for the uncoated piles (C and D) reveals that there are clear differences in the settlement of the pile top and the contraction of the

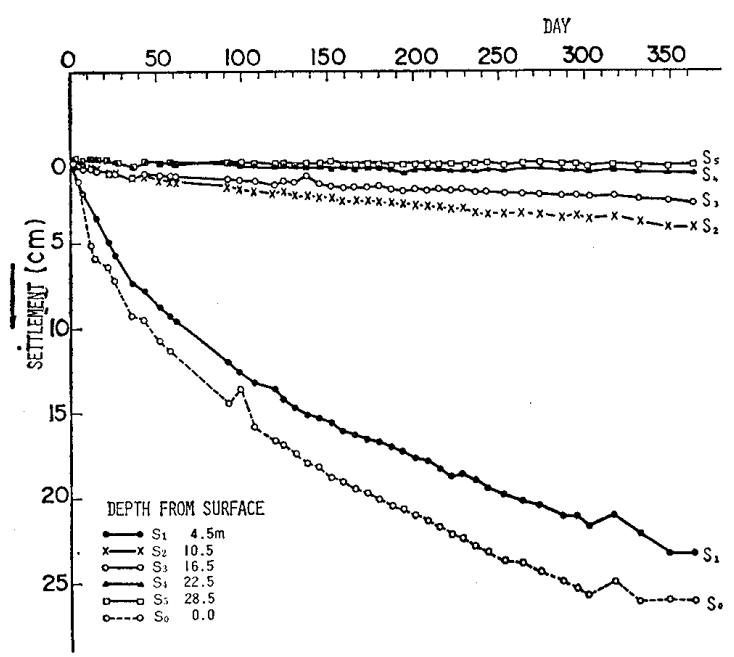

Fig. 20. Settlement of ground
Table 2. Contraction of pile and settlement of pile top and pile tip ( $\mathrm{mm}$ )

\begin{tabular}{l|c|c|c|c}
\hline & \multicolumn{2}{|c|}{ Coated pile } & \multicolumn{2}{c}{ Uncoated pile } \\
\cline { 2 - 5 } & A & B & C & D \\
\hline Contraction of pile & 2.02 & 1.65 & 2.85 & 4.13 \\
\hline Settlement of pile top & 2.07 & 0 & 6.21 & 5.18 \\
\hline Settlement of pile tip & 0.05 & -1.65 & 3.36 & 1.05 \\
\hline
\end{tabular}

piles; both values are larger for the uncoated piles than for the coated piles. In particular, the top settlement dimensions of the uncoated piles are $5 \sim 6 \mathrm{~mm}$, whereas those of the coated piles are almost zero (see Table 2). The effect of the negative skin friction can be seen in this fact.

Strain in the pile shafts increases with time, and continues to increase gradually even after one year, as indicated in Fig. 21. The distributions of axial force, bending moment, and contraction, which can be calculated from the strain data, are shown in Fig. 22 for pile A (coated pile) and in Fig. 23 for pile $\mathrm{C}$ (uncoated pile). The values shown were calculated and plotted in approximately four-month intervals. The effect of the asphalt coating in decreasing the negative skin friction is clearly seen in the fact that the axial force induced in the coated piles is small while that in the uncoated piles is large. The large bending moment induced in the upper part about $10 \mathrm{~m}$ from the original ground surface for both coated and uncoated piles corresponds with the distribution of ground settlement. The magnitude of bending moment of the coated piles is a little larger than that of the uncoated piles. While the difference is slight, this result 


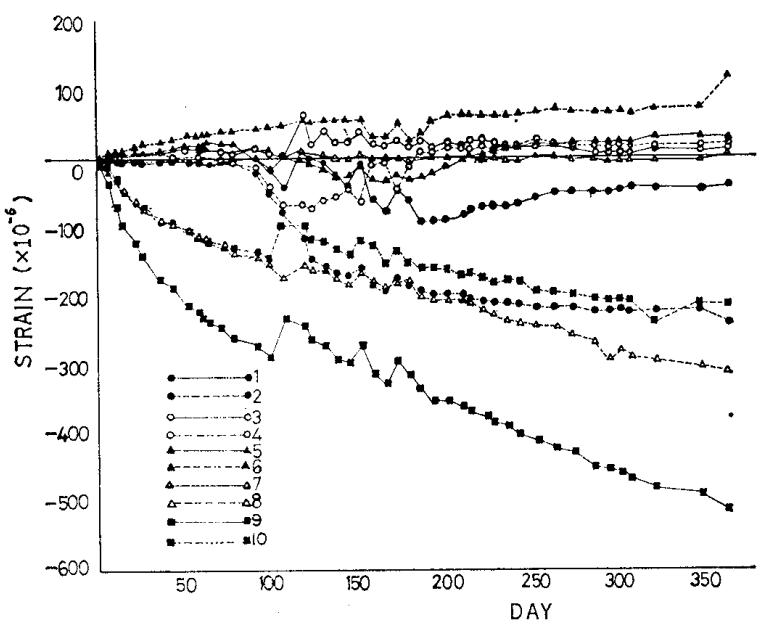

(a) on upper surface

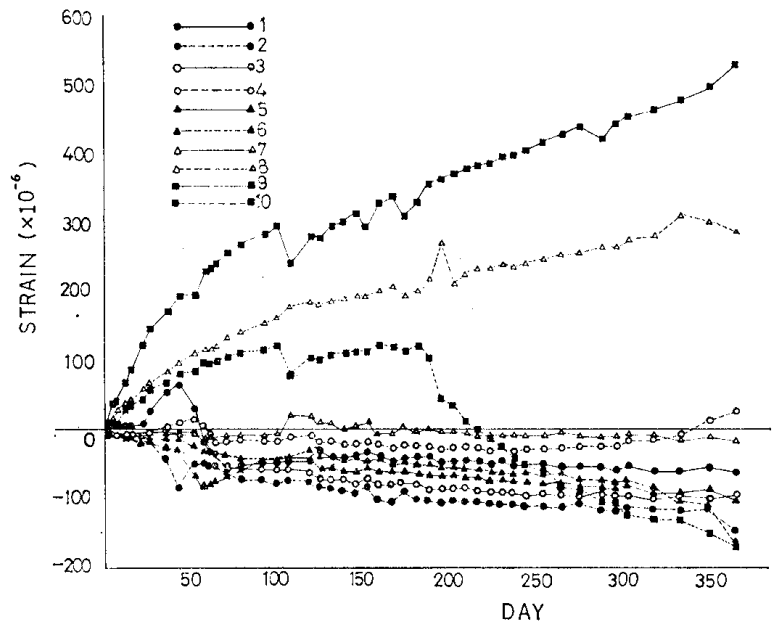

(b) on lower surface

Fig. 21. Shaft strain of pile A (coated pile)

implies that the asphalt coating is disadvantageous from the point of view of the bending of a batter pile.

The maximum bending moment is plotted against the ground surface settlement in Fig. 24. The relation between these two values seems to be almost proportional in the field tests as well as in the model tests. Furthermore, the difference in the magnitude of maximum bending moments between the coated piles and the uncoated piles is clearly shown in Fig. 24.

\section{NUMERICAL ANALYSIS OF FIELD TESTS}

Two-dimensional finite element analysis

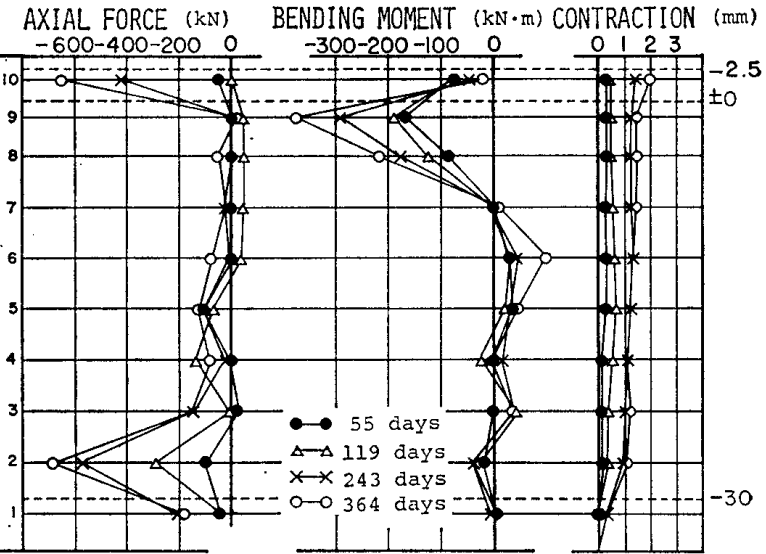

Fig. 22. Measured results of pile $A$ (coated pile)

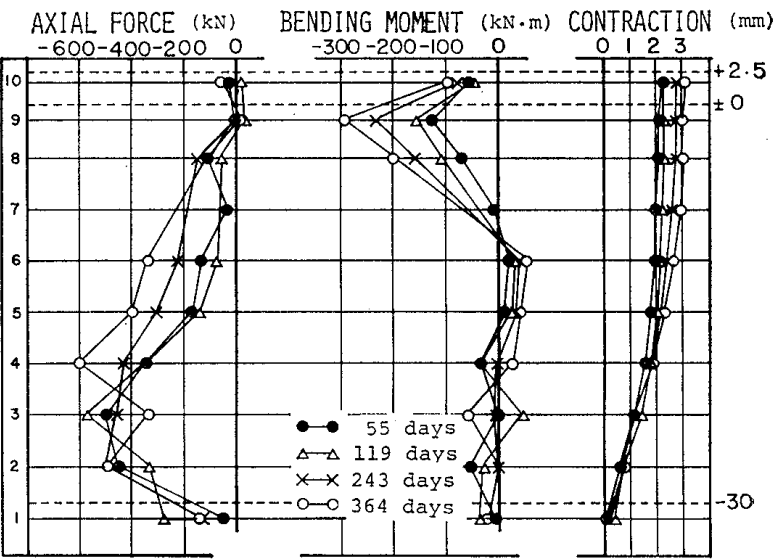

Fig. 23. Measured results of pile $C$ (uncoated pile)

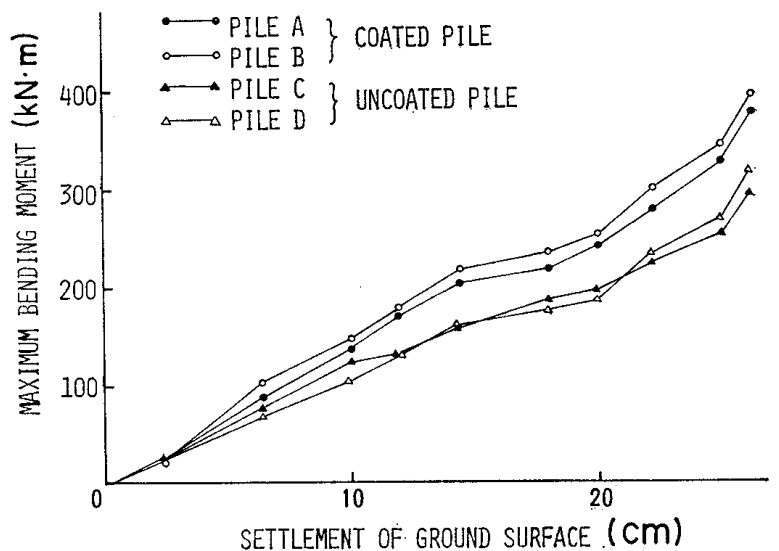

Fig. 24. Maximum bending moment versus settlement of ground surface

was performed for the field data, but it could not express actual behavior. This is 
Table 3. Case of calculation by Sato's method

\begin{tabular}{l|c|c|c|c}
\hline $\begin{array}{l}\text { Case of } \\
\text { calculation }\end{array}$ & $\begin{array}{l}\text { Width } \\
\text { factor }\end{array}$ & $\begin{array}{c}\text { "Effective } \\
\text { length" }\end{array}$ & $\begin{array}{l}\text { Length in } \\
\text { Winkler } \\
\text { ground }\end{array}$ \\
\hline \multirow{3}{*}{ Case 1 } & $\mathrm{a}$ & 2 & $7.0 \mathrm{~m}$ & $30.8 \mathrm{~m}$ \\
\cline { 2 - 5 } & $\mathrm{b}$ & 3 & 7.0 & 30.8 \\
\hline \multirow{5}{*}{ Case 2 } & $\mathrm{c}$ & 5 & 7.0 & 30.8 \\
\hline \multirow{5}{*}{ Case 3 } & $\mathrm{b}$ & 2 & 8.0 & 29.8 \\
\hline & $\mathrm{c}$ & 5 & 8.0 & 29.8 \\
\hline \multirow{5}{*}{ Case 4 } & $\mathrm{b}$ & 3 & 8.0 & 29.8 \\
\hline & $\mathrm{c}$ & 5 & 9.0 & 28.8 \\
\hline & $\mathrm{a}$ & 2 & 9.0 & 28.8 \\
\hline & $\mathrm{b}$ & 3 & 9.0 & 28.8 \\
\hline & $\mathrm{c}$ & 5 & 10.0 & 27.8 \\
\hline
\end{tabular}

because a batter pile is modeled by an infinitely wide inclined wall in a two-dimensional analysis.

The twelve cases listed in Table 3 were calculated by Sato's method. In this calculation, the free length is $90 \mathrm{~cm}$, the degree of consolidation $U=40 \%$ from the standard consolidation tests, the width factor is varied among three values, and the "effective length" is varied among four values. Based on the two formulae

$$
\begin{aligned}
& q_{u}\left(\mathrm{kgf} / \mathrm{cm}^{2}\right)=\frac{1}{8} N \quad(\mathrm{Fujita}, 1979) \\
& k\left(\mathrm{kgf} / \mathrm{cm}^{3}\right)=0.15 N
\end{aligned}
$$

the elastic soil reaction coefficient $k$ is assumed to vary linearly with the depth in the same manner as $q_{u}$ (the second equation represents the middle value between the center and the lower bound of the relation for estimating the horizontal pile resistance, after Yokoyama, 1977). The best agreement is obtained in the case 4 , in which the "effective length" is $10 \mathrm{~m}$, as indicated in Fig. 25, which also reveals the great influence of the width factor $\alpha$ on the results. Furthermore, the calculated depths of maximum bending moment are different from those obtained by measurement, even though the important calculation values had been varied in an effort to obtain good agreement.

As a model for the author's method, a pile is divided into four sections: the free portion, the part in the embankment, the

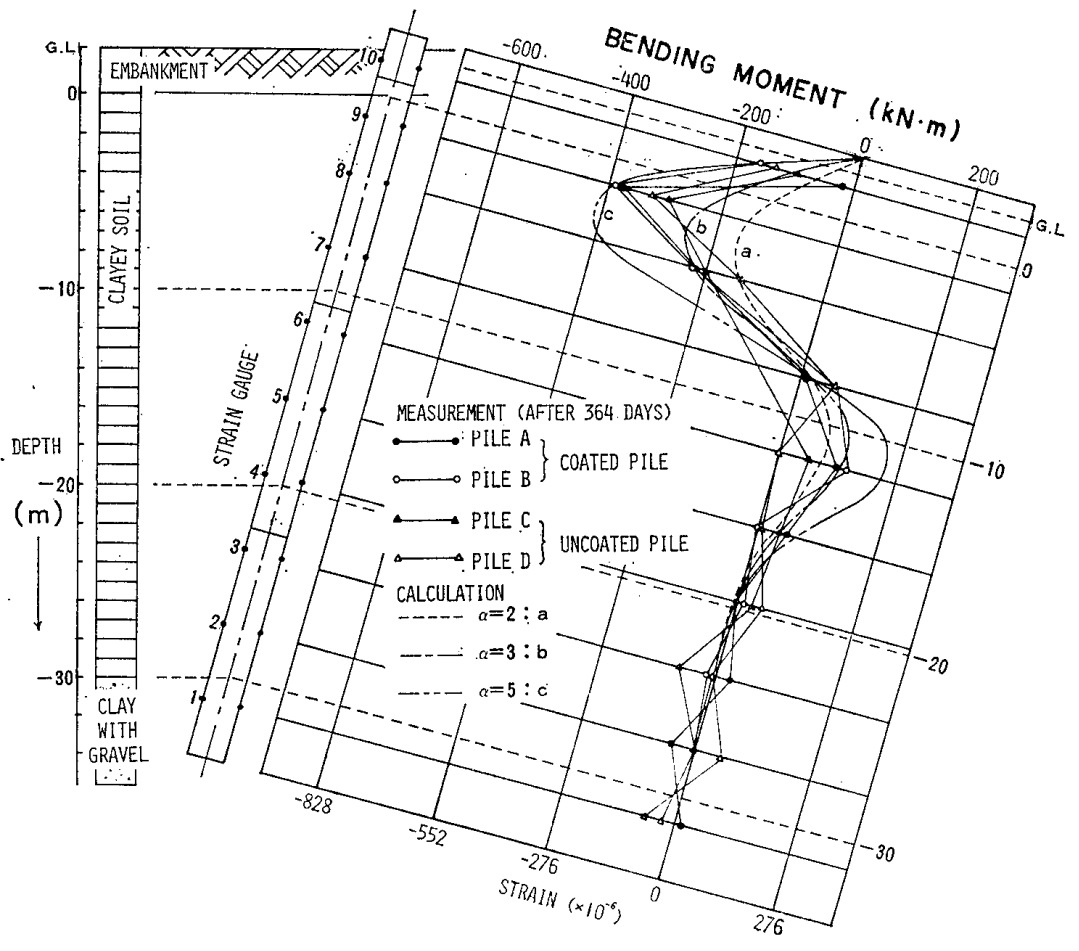

Fig. 25. Calculated results by Sato's method (Case 4) where $a$ means width factor

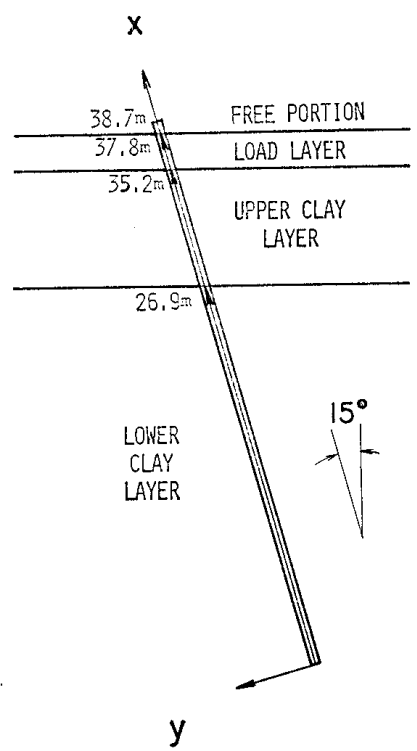

Fig. 26. Model of the author's method for the field tests 


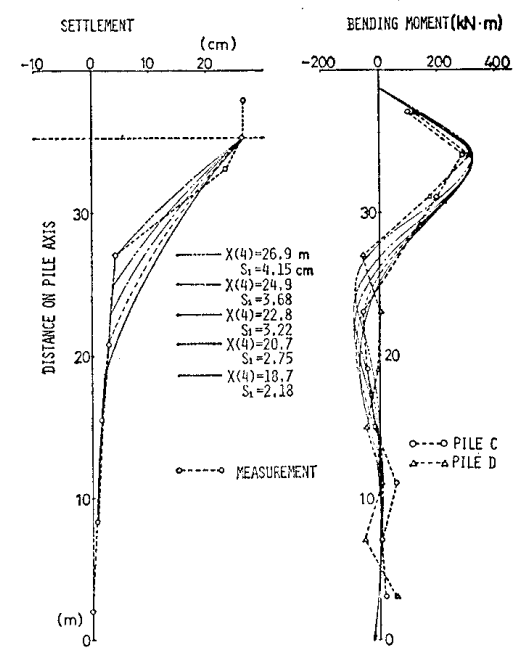

Fig. 27. Influence of the difference in depth of the boundary between upper and lower clay layers, where $x(4)$ is the position of the boundary in the coordinate shown in Fig. 26, and $S_{1}$ is the subsidence at the boundary

part in the upper clay layer, and the part in the lower clay layer (from top to bottom). The reason the clay layer is divided into two parts is because of the clear change in the settlement distribution shown in Fig. 19. The settlements in these two layers are expressed by the equivalent-layer method presented by Palmer and Brown (1957), which is a simple method of calculating the consolidation of clay layers by modifying the thickness of each layer in inverse proportion to the root of the consolidation coefficient $c_{v}$.

The model is illustrated in Fig. 26. The unit weight of the embankment is $14.8 \mathrm{kN} /$ $\mathrm{m}^{3}$, the width factor is assumed to be 3 in accordance with Sato et al. (1970), and Broms (1964). This condition is the same as that which has a unit weight of 44.4 $\mathrm{kN} / \mathrm{m}^{3}$, and a width factor of unity. The assumed coefficients of subgrade reaction are $3 \mathrm{MN} / \mathrm{m}^{3}$ for the upper clay layer and $6 \mathrm{MN} /$ $\mathrm{m}^{3}$ for the lower clay layer, based on $q_{u}$ in Fig. 19. Each value is varied, as shown later in Figs. 30 and 31, to examine its influence and its appropriateness.

The depth of the boundary between the upper and lower clay layers must be deter-

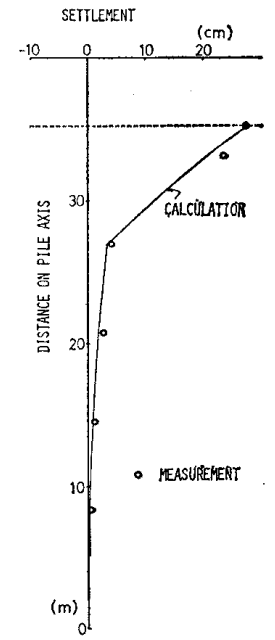

Fig. 28. Settlement distribution obtained by the almost precise one-dimensional consolidation analysis (Kobayashi, 1976)

mined first. The calculation results from the varying thicknesses of the upper clay layer at $8 \mathrm{~m}, 10 \mathrm{~m}, 12 \mathrm{~m}, 14 \mathrm{~m}$, and $16 \mathrm{~m}$ are shown in Fig. 27. The best agreement is obtained when the upper clay layer thickness is $8 \mathrm{~m}$, which means that the distance from the pile tip to the boundary in the direction of the pile axis is $26.9 \mathrm{~m}$, as seen in Fig. 27. Furthermore, the results obtained under this condition agree well with those found by an extremely sophisticated consolidation analysis using finite elements (Kobayashi 1976). The calculated line in Fig. 28 is obtained by this finite element analysis using the results from the standard consolidation test, and is considered almost as precise a solution as is possible in the case of one-dimensional consolidation for a ground with two clay layers.

Fig. 29 represents the difference when the width factor of the load layer is varied among the three values of 1,3 , and 10, which have the same meaning as their unit weight of $14.8,44.4$, and $148 \mathrm{kN} / \mathrm{m}^{3}$. The influence is negligible, as seen from the difference in the bending moment distribution in the lefthand figure. Fig. 30 reveals the influence of the reaction coefficient of the upper clay layer. This factor has a larger influence than the others, and the best agreement is obtained by the value of $3 \mathrm{MN} / \mathrm{m}^{3}$, which 


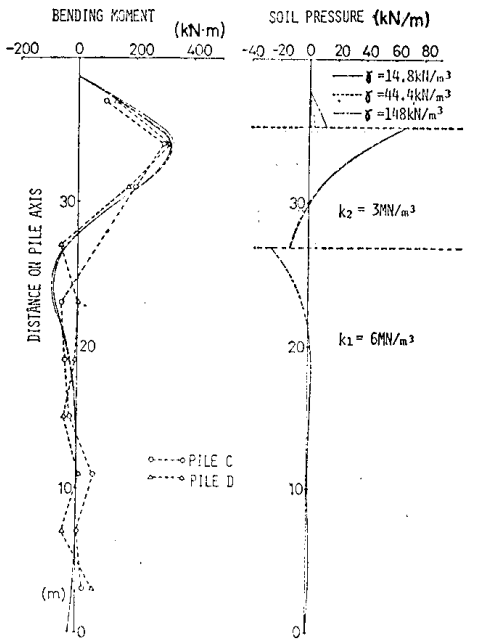

Fig. 29. Influence of the difference in unit weight of the load layer

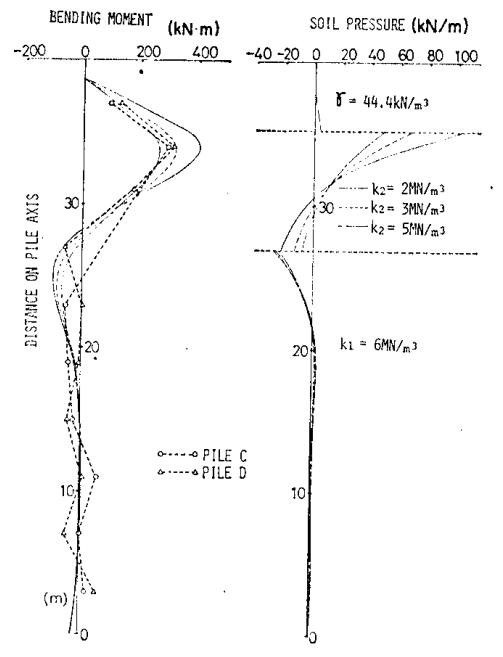

Fig. 30. Influence of the difference in reaction coefficient of the upper clay layer

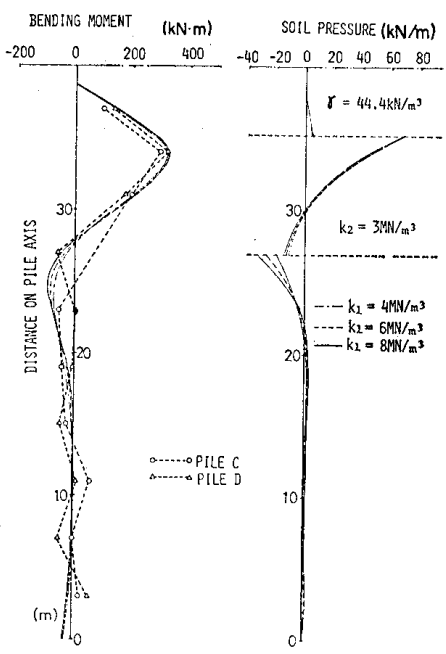

Fig. 31. Influence of the difference in reaction coeffcient of the lower clay layer was estimated from the soil properties. Fig. 31 indicates that the influence of the reaction coefficient of the lower clay layer is negligible.

In this calculation, it seems reasonable to assume the embankment to be the load layer in the model. Although the thickness of the load layer is an essential factor in Sato's method, it has very little significance in the author's method, and it is meaningful as a substitute for Winkler subsoil near the surface.

\section{CONCLUSIONS}

An analytical method of examining the flexural behavior of a batter pile has been proposed; Winkler subsoil is assumed, and an electronic computer is used for calculation. In order to prove the usefulness of this method, both laboratory and field tests were conducted. In the field tests, the effect of asphalt coating was also studied. Apart from the author's method, the finite element method and Sato's method were also examined. The main conclusions drawn from the study are as follows :

(1) The bending moment increases with time and approaches a stable value.

(2) The maximum bending moment is proportional to the pile inclination and to the ground surface settlement.

(3) Although the asphalt coating seems useful for the negative skin friction for a batter pile as well, it seems disadvantageous from the point of view of bending.

(4) Although three-dimensional finite element analysis provides reasonable results, two-dimensional finite element analysis is unable to simulate the bending of a batter pile.

(5) While satisfactory results were obtained by Sato's method for both laboratory and field tests, it seems difficult, in general, to determine the "effective length" which is essential in this method.

(6) The best approximation was obtained with the author's method for both laboratory and field tests. This method provides a stable solution by simple estimation of soil constants and calculation of consolidation.

(7) Palmer's method is useful in the author's analysis when a ground has double clay layers.

\section{ACKNOWLEDGEMENT}

The author's method was developed originally with Prof. Sawaguchi of Tsukuba University. This is indicated by the presence 
of his name in Ref.13, which was published when he was the author's superviser at Port and Harbour Research Institute. The author expresses his sincere gratitude to Prof. Sawaguchi. The model tests were conducted in the author's laboratory by collaborators from the Japanese Association for Steel Pipe Piles.

\section{REFERENCES}

1)Broms, B. (1964) : "Lateral resistance of piles in cohesionless soils," Proc. of ASCE, Vol. 90, No. SM 3, pp. 123-156.

2)Broms, B. and Fredriksson, A. (1976): "Failure of pile-supported structures caused by settlements," Proc. of 6 th European Conference on SMFE, Vol. 1.2, pp.383-386.

3)Endo, M. (1969): "Negative skin friction," Library of Found. Eng., No.6, Japanese Soc. of SMFE, pp. 257-315 (in Japanese).

4)Fujita, K. (1979) : "Standard penetration test," Library of Found. Eng., No. 4, 2 nd Ed., Japanese Soc. of SMFE, pp. 33-90 (in Japanese).

5)Kobayashi, M. (1976) : "Solutions of consolidation problems by finite elements," Tech. Note of the Port and Harbour Research Institute, No. 247, 14 p. (in Japanese).

6) Mikasa, M. (1963) : The Consolidation of Soft Clay, Kajima Institution Publishing Co., Ltd. (in Japanese).

7)Palmer, L. A. and Brown, P.P. (1957) : "Settlement analysis for areas of continuing subsidence," Proc. of 4 th International Conference on SMFE, Vol.1, pp. 395-398.

8)Sato, A., Akai, K. and Funahashi, T. (1970): "Study on methods to calculate negative skin friction and bending of a batter pile," Laboratory Report of Japan Road Corporation, pp. 31-49 (in Japanese).

9)Sawaguchi, M. (1971) : “Approximate calculation of negative friction of a pile," Soils and Foun- dations, Vol.11, No. 3, pp. 31-49.

10)Shibata, T., Sekiguchi, H. and Yukitomo, H. (1982): "Model test and analysis of negative friction acting on piles," Soils and Foundations, Vol. 22, No. 2, pp. 29-39.

11) Shibata, T., Sekiguchi, H. and Yukitomo, H. (1984) : Closure on "Model test and analysis of negative friction acting on piles," Soils and Foundations, Vol. 24, No.1, pp. 171-172.

12) Takahashi, K., Sawaguchi, M., Zen, K., Shinohara, K. and Hashimoto, K. (1974): "Experiment and study on negative skin friction on piles (1 st Report)," Report of the Port and Harbour Research Institute, Vol.13, No.1, pp.65-86 (in Japanese).

13) Takahashi, K. and Sawaguchi, M. (1976) : "Experimental study on negative skin friction ( 2 nd Report)-Field experiment of asphalt coated piles-," Report of the Port and Harbour Research Institute, Vol.15, No.3, pp.21-51 (in Japanese).

14) Takahashi, K. and Sawaguchi, M. (1978): "Experimental study on the bending of battered piles due to ground settlement," Report of the Port and Harbour Research Institute, Vol. 17, No. 4, pp. 121-167 (in Japanese).

15) Takahashi, K. (1980): "Problems related to the design of pile foundation in port and harbour," Proc. of 1980 Annual Research Presentation of the Port and Harbour Research Institute, pp. 83-155 (in Japanese).

16) Takahashi, K. (1981): "Experimental study on the bending of batter piles due to ground settlement (2 nd Report)-Field Experiment-," Report of the Port and Harbour Research Institute, Vol. 20, No.2, pp. 127-168 (in Japanese).

17) Terzaghi, K. (1943) : Theoretical Soil Mechanics, John Wiley and Sons, Inc.

18) Yokoyama, Y. (1977) : Calculation Methods and Examples of Structures with Piled Foundation, Sankaido (in Japanese). 